\title{
CAPITULO VII
}

\section{ESTRUCTURA Y FORTALECIMIENTO DEL CONTROL FISCAL TERRITORIAL - DIAGNÓSTICO Y PROPUESTA ${ }^{71}$}

\section{STRUCTURE AND STRENGTHENING OF TERRITORIAL FISCAL CONTROL - DIAGNOSIS AND PROPOSAL}

Coautores:

Juan Diego Doncel Ramírez. Administrador de Empresas de la Universidad Pedagógica y Tecnológica de Colombia UPTC. Especialista en Gobierno Municipal de la Universidad Javeriana, Especialista en Control Organizacional y de Gestión de la Universidad de los Andes, Especialista en Gestión Pública de la Escuela Superior de Administración Pública ESAP. Profesional Especializado Auditoría Auxiliar AGR.

Tatiana Ordóñez Vásquez. Abogada de la Universidad del Rosario. Magister en Derecho Administrativo de la Universidad Militar, Especialista en Instituciones Jurídico-Procesales de la Universidad Nacional de Colombia y Especialista en Derecho Administrativo de la Universidad Santo Tomás. Profesional Especializado Auditoría Auxiliar AGR. Docente de posgrado, e investigadora del "Observatorio de Política Pública del Control Fiscal" adscrito -según convenioa la Auditoría General de la República y la Universidad Santo Tomás de Bogotá.

Liliana Patricia Ortiz Ospino, Ingeniera Industrial de la Universidad del Norte, Magíster en

71 Documento elaborado en diciembre de 2017 por un equipo de especialistas de la Auditoría General de la República - AGR, con la colaboración de los doctores Guillermo E. Tuta y Gustavo A. Escudero; y presentado al CONPES en desarrollo del compromiso adquirido por la entidad. 
Políticas Públicas de la Universidad de los Andes y Especialista en Gerencia y Gestión Cultural de la Universidad del Rosario. Docente investigador de pregrado y posgrado y Profesional Especializado Oficina de Estudios Especiales y Apoyo Técnico de la AGR e investigadora del "Observatorio de Política Pública del Control Fiscal" adscrito -según convenio- a la Auditoría General de la República y la Universidad Santo Tomás de Bogotá.

Ana Esther Tovar Porras. Administradora Pública de la Escuela Superior de Administración Pública ESAP, Especialista en Planeación Estratégica del Control interno de la Universidad Libre. Asesora del Despacho del Auditor General de la República.

Armando Rodríguez Ángel. Administrador Público de la Escuela Superior de Administración Pública ESAP, Especialista en Finanzas de la Universidad del Rosario, y Especialista en Presupuesto también de la ESAP. Asesor del Despacho del Auditor General de la República.

Ximena Salazar Quintero. Ingeniera industrial de la Universidad del Norte, Especialista en Gerencia de Proyectos de Ingeniería de la Universidad EAN. Asesora del Despacho del Auditor General de la República.

\section{Resumen}

Varios estudios propiciados por la academia, la Auditoría General de la República (AGR), otros órganos de control fiscal del nivel nacional y territorial, y organismos multilaterales como el Banco Mundial, además de deliberaciones y conclusiones de diversos foros y eventos técnicos, han dado cuenta de la perentoria necesidad de fortalecer el control fiscal en Colombia, particularmente, en lo atinente al control fiscal territorial como elemento fundamental de la descentralización y de la democracia local.

El objetivo de este documento fue “Desarrollar una evaluación y propuesta sobre la estructura del control fiscal territorial", compromiso adquirido por la Auditoría General de la República (AGR) en el CONPES 167 de 2013, actividad número 110 (5.20) del componente principal de la Política Pública Integral Anticorrupción (PPIA).

En consecuencia, desde una mirada eminentemente técnica, se propusieron en diciembre de 2017 estos elementos de análisis, para ordenar el debate de la agenda pública, en la medida en que la reforma sustancial en materia de control fiscal, como la que se plantea, requiere ilustración técnica, no obstante tener un carácter esencialmente político e interesar al conjunto de la sociedad. 
No obstante contener propuestas elaboradas en diciembre de 2017, cobra especial relevancia el texto dado que fue tenido como insumo para las discusiones que en el seno del Congreso de la República implicó la expedición del Acto Legislativo 04 de 18 de septiembre de 2019, por el cual se reforma el control fiscal colombiano.

En consecuencia, las 12 principales propuestas que hasta diciembre de 2017 había venido acopiando, sistematizando y propiciando la Auditoría General de la República como organismo de control fiscal de segundo nivel, en su condición de auditora de los contralores; basadas en diagnósticos recurrentes y actualizados, y que se sintetizan, a título de hipótesis, así: 1) Corregir la estructura difusa del control fiscal; 2) Otorgar la función preventiva al control fiscal; 3) Medidas para mejorar el resarcimiento del daño al patrimonio público; 4) Garantizar la autonomía de los órganos de control fiscal territorial; 5) Un nuevo modo de cálculo presupuestal para las contralorías territoriales; 6) Superar la fractura entre el control fiscal interno y el control fiscal externo; 7) Desarrollar la carrera administrativa especial en las contralorías territoriales; 8) Fortalecer la capacidad sancionatoria de las contralorías territoriales y de la AGR; 9) Medición de resultados beneficios del control fiscal; 10) Tecnología para mejorar la calidad y cobertura del control; 11) Control social para el fortalecimiento del control fiscal, y finalmente 12) Ampliación del periodo constitucional del Auditor General de la República.

\section{Abstract}

Several studies promoted by the academy, the General Audit Office of the Republic (AGR), other fiscal control bodies of the national and territorial level, and multilateral organizations such as the World Bank, in addition to deliberations and conclusions of many forums and technical events, have realized the urgent need to strengthen Colombian fiscal control, particularly as regards territorial fiscal control as a fundamental element of decentralization and local democracy.

The objective of this document was"to develop an evaluation and a proposal on the structure of territorial fiscal control", a commitment acquired by the General Audit of the Republic (AGR) in CONPES 167 of 2013, activity number 110 (5.20) of the main component of the Comprehensive Public Anti-Corruption Policy (PPIA).

Consequently, from an eminently technical perspective, these elements of analysis were proposed in December 2017, to order the debate on the public agenda, to the extent that substantial tax control reform, such as the one proposed, requires technical illustration, despite having an essentially political character and interest the whole society. 
Despite containing this proposals made in December 2017, the text is particularly relevant since it was taken as input for the discussions that within the Congress of the Republic involved the issuance of Legislative Act 04 of September 18, 2019, whereby Colombian fiscal control is reformed.

Consequently, the 12 main proposals that until December 2017 had been collecting, systematizing and propitiating the General Audit of the Republic as a second level fiscal control body, in its capacity as auditor of the comptrollers; based on recurrent and updated diagnoses, and which are synthesized, by way of hypothesis, as follows: 1) Correct the diffuse structure of fiscal control; 2) Grant the preventive function to the fiscal control; 3) Measures to improve compensation for damage to public assets; 4) Guarantee the autonomy of the territorial fiscal control bodies; 5) A new mode of budgetary calculation for territorial comptrollers; 6 ) Overcome the fracture between internal fiscal control and external fiscal control; 7) Develop the special administrative career in the territorial comptrollers; 8) Strengthen the sanctioning capacity of territorial controllers and the AGR; 9) Measuring results benefits of fiscal control; 10) Technology to improve the quality and coverage of the control; 11) Social control to strengthen fiscal control, and finally 12) Extension of the constitutional period of the Auditor General of the Republic.

\section{Palabras clave}

Control fiscal, control social, estructura del control fiscal territorial.

\section{Keywords}

Fiscal control, internal control, social control, structure of territorial fiscal control

Temario: Introducción. 7.1. Contexto y diagnóstico. 7.2. Diagnóstico y propuesta de solución 7.3. Conclusiones. 7.4. Lista de referencias

\section{Introducción}

Con el objeto de "Desarrollar una evaluación y propuesta sobre la estructura del control fiscal territorial", para atender el compromiso adquirido por la Auditoría General de la República (AGR) en el CONPES 167 de 2013, actividad número 110 (5.20) del componente principal de la Política Pública Integral Anticorrupción (PPIA); desde una mirada eminentemente técnica, se propusieron en diciembre de 2017 elementos de análisis, para ordenar el debate de la agenda pública, a título de ilustración técnica como insumo para una reforma sustancial en materia de control fiscal, que no obstante tener un carácter esencialmente político, interesa a toda la 


\section{OPPCF}

sociedad.

El 9 de diciembre de 2013, en conmemoración del día mundial de lucha anticorrupción, se expidió el Documento CONPES 167 de 2013 “Estrategia Nacional de la Política Pública Integral Anticorrupción", con el objetivo principal de fortalecer las herramientas y mecanismos institucionales para la prevención, investigación y sanción de la corrupción en el país, mediante cinco (5) estrategias:

- Mejorar el acceso y la calidad de la información pública para prevenir la corrupción.

- Mejorar las herramientas de gestión pública para prevenir la corrupción.

- Aumentar la incidencia del control social en la lucha contra la corrupción

- Promover la integridad y la cultura de la legalidad en el Estado y la sociedad.

- Reducir la impunidad en actos de corrupción.

En el numeral VIII del Documento CONPES 167 se recomendaba, entre otras acciones:

11. Sugerir a la Fiscalía General de la Nación, a la Procuraduría General de la Nación y a la Auditoría General de la República contribuir con el mejoramiento del acceso y la calidad de la información pública para la prevención de la corrupción.

12. Sugerir a la Procuraduría General de la Nación y a la Auditoría General de la República, adelantar gestiones para mejorar las herramientas de gestión pública, promover el control social, la integridad y la cultura de la legalidad en el Estado y la sociedad, conforme a lo establecido en el plan de acción. (Resaltado fuera del texto)

El Plan de Acción del CONPES 167 contenía 110 acciones concertadas con entidades y dependencias del ejecutivo nacional y órganos de control con sus respectivos indicadores de cumplimiento, metas, plazos y responsables.

En ese sentido, la Auditoría General de la República (AGR), asumió el compromiso señalado en la acción número 110 (5.20) consistente en “Desarrollar una evaluación y propuesta sobre la estructura del control fiscal territorial".

El documento contiene los resultados de la evaluación, con apoyo en diversos estudios y propuestas de la academia, organismos multilaterales y otras autoridades en el tema, así como de contralorías. Fue elaborado por especialistas de distintas disciplinas profesionales, formación y experiencias en materia de control fiscal.

Para ello, también se hizo referencia a los compromisos de otras entidades con relación al control fiscal y que han sido incorporadas al plan de acción del Documento CONPES 167, porque son fundamentales para garantizar una óptima "estructura del control fiscal territorial" 
y complementan los compromisos de la AGR frente al tema bajo su responsabilidad.

En efecto, el Plan de Acción del Documento CONPES incluyó, entre otras, las siguientes acciones, que directa o indirectamente inciden en la "estructura del control fiscal territorial", en su eficiencia y efectividad:

1.17 Desarrollar plataforma tecnológica integrada para el ejercicio de la función fiscalizadora - según lo dispuesto el artículo 126 de la Ley 1474 de 2011 (Estatuto Anticorrupción). Integración de Sistemas de Información para el control fiscal. (AGR)

2.4 Presentar un proyecto de ley para crear la carrera administrativa de las contralorías territoriales y modificar la forma de elección de los contralores territoriales, para garantizar la transparencia de dichos procesos. (Mininterior)

2.32 Promover y desarrollar estudios técnicos y metodologías para el ejercicio de control y vigilancia de los recursos públicos. (AGR)

5.3 Elaborar una ruta crítica para lograr mayor efectividad en la recuperación de activos producto de hechos de corrupción. (DAPRE-Secretaría de Transparencia)

5.15 Realizar una mesa técnica con las entidades competentes para elaborar una propuesta de articulación de sistemas de información de los procesos penales, fiscales y disciplinarios. (DAPRE. Secretaría de Transparencia)

5.20 Desarrollar una evaluación y propuesta sobre la estructura del control fiscal territorial. (AGR). Las referencias a las entidades responsables en cursiva no hacen parte del texto.

Aunque una primera lectura y estudio de la política anticorrupción incorporada en el Documento CONPES 167 permite concluir un acertado enfoque preventivo, éste es un elemento ausente en las normas que regulan los órganos de control fiscal.

Por ejemplo, el Ministerio Público dispone de facultades preventivas, mientras que el control fiscal en Colombia, por disposición constitucional es posterior y selectivo (Const., 1991, art. 267), de manera que solo puede pronunciarse una vez culminadas las diferentes actividades, operaciones y procesos, según lo ordena la Ley 42 de 1993.

Artículo $5^{\circ}$. Para efecto del artículo 267 de la Constitución Nacional se entiende por control posterior la vigilancia de las actividades, operaciones y procesos ejecutados por los sujetos de control y de los resultados obtenidos por los mismos. Por control selectivo se entiende la elección mediante un procedimiento técnico de una muestra representativa de recursos, cuentas, operaciones o actividades para obtener conclusiones sobre el universo respectivo en el desarrollo del control fiscal.

La necesidad de un enfoque preventivo del control fiscal constituye un elemento fundamental para la efectividad de esta función pública en la lucha contra la corrupción.

De persistir el enfoque actual, las contralorías del país seguirán condenadas a fungir como notarios de los descalabros patrimoniales, máxime cuando la mayoría de los casos emblemáticos de corrupción demuestran que el daño al patrimonio público en lo fundamental 
es irreparable, como se verá líneas adelante.

El tema de la estructura del control fiscal, también se enfrenta a problemas como la ausencia de autonomía presupuestal, la falta de independencia frente a los vigilados, la forma de elección de los contralores, la demora en la reglamentación de la carrera administrativa especial de los servidores públicos de las contralorías, entre otros asuntos que el presente documento aborda de manera integral y sistémica, como requisito para la construcción de un verdadero y eficiente Sistema Nacional - Territorial del control fiscal colombiano, tarea pendiente en la legislación y en la práctica de tan importante función pública.

\subsection{CONTEXTO Y DIAGNÓSTICO}

En el último trimestre de 2017 el debate público frente a las elecciones para Presidente y Congreso de la República, se ha venido centrando cada vez con mayor fuerza en el tema de la corrupción. Es claro que resulta complicado hacer aproximaciones sobre la cuantía que todos los días pasa de los presupuestos públicos a hinchar los bolsillos de los corruptos. Según el Contralor General, Edgardo Maya: "este flagelo le cuesta al país 50 billones de pesos al año: vale decir, casi un billón de pesos por semana" (El Tiempo, 2017).

Cifra que todavía estaría muy por debajo de la realidad, pues no se aclara si ese valor incluye lo que se perdió en la Refinería de Cartagena -REFICAR, que tuvo sobrecostos por encima de cuatro mil millones de dólares (El Espectador, 2016), parte de los cuales se perdió por corrupción. O lo que significó la reciente venta de ISAGEN como pérdida de un activo muy productivo para la Nación.(Revista Dinero, 2016).Tampoco se informa sobre lo que se pierde todos los días por el incuantificable daño ambiental, incluido el que genera la explotación irracional de los recursos naturales, que constituye una forma de usufructo legalizado contra el interés general, por parte de las grandes compañías transnacionales de la mega minería y también por la explotación ilegal de empresas mineras en cabeza de distintas mafias que operan en los territorios.

Hace poco más de un año, comenzaron a regir los nuevos planes de desarrollo en cada uno de los 1.102 municipios y 32 departamentos que tiene Colombia, para el período junio 2016 - mayo 2020, planes que se ejecutan a través de los presupuestos de inversión anuales, especialmente mediante la figura de la contratación pública. Y aquí también la corrupción hace su agosto, sin medidas de control efectivas en las distintas etapas del proceso de ejecución de los programas y proyectos.

Naturalmente que ese fenómeno de la corrupción es global, multidimensional y generalizado; 
abarca las distintas ramas del poder público y también a los particulares. No es un fenómeno que involucra exclusivamente causales como la ausencia de controles, entre ellos el control fiscal. Pero digamos sin temor a equivocarnos, que el modelo de control fiscal en Colombia, los organismos que lo ejercen, las normas y políticas que lo rigen son funcionales a un modelo perverso de des-administración que propicia la corrupción, pues carece de instrumentos legales preventivos y de herramientas oportunas para detectar y evitar el daño patrimonial.

En efecto, el modelo de control fiscal al manejo de los recursos públicos no es independiente de sus vigilados, no controla con eficacia, eficiencia ni efectividad porque no puede legalmente "advertir" o comunicar alertas tempranas que prevengan el daño al erario público. Ni siquiera puede operar como un sistema cohesionado con políticas que orienten su efectividad, porque ha sido ideado por quienes diseñan y adoptan las políticas públicas con el criterio de no "entorpecer" la gestión de la administración y de los particulares que manejan los recursos públicos. Y entonces, solamente puede examinar y pronunciarse tardíamente, una vez ejecutadas las distintas actividades, operaciones y procesos administrativos.

De este modelo de control se están aprovechando los intereses particulares de aquellos para quienes "todo vale" a la hora de incrementar sus ingresos, así sea de manera dolosa. Aquellos que tienen como objetivo aumentar sus tasas de ganancia, sin ningún escrúpulo ni asomo ético.

De igual forma, el modelo de "administración" del patrimonio público se ha venido deformando de manera preocupante, hasta límites insospechados, donde hoy, algunas acciones y políticas adoptadas por quienes deberían proteger los recursos públicos y el interés general -como lo ordena la Constitución- favorecen y apadrinan las más oscuras transacciones (caso Odebrecht, entre tantos otros), debilitando al máximo las instituciones del Estado. Pareciera que estuviese emergiendo una nueva política orientada a que los recursos públicos se pongan al servicio de los grandes negocios, anulando cualquier intención constitucional sobre la "libre competencia" y la "función social y ecológica de la propiedad privada". Entonces, "dejar hacer, dejar pasar", pareciera ser también la nueva consigna del actual modelo de control fiscal, modelo sobre el que no ha sido posible su reforma y fortalecimiento para evitar que sea funcional a aquellos intereses venales.

Y ni hablar del control interno, en cabeza de la misma administración. El control al manejo de los recursos públicos se cumple en primera instancia a través de la operación del control interno que le compete a cada entidad pública. Este control interno se complementa con el control fiscal externo posterior y selectivo a cargo de las contralorías. El control interno creado por la Constitución Política y reglamentado por la ley, está basado en el "autocontrol", 
la "autogestión” y la "autorregulación". Todos los servidores públicos, -incluida la alta dirección al interior de las entidades y organismos del Estado-, deberían vigilar y controlar la gestión de los recursos públicos en sus distintos momentos: de manera previa, simultánea y también posterior. Al control interno adecuadamente implementado le correspondería ofrecer a la sociedad, -como legítima propietaria de los bienes y recursos públicos-, seguridad razonable sobre el buen manejo y uso de los mismos, la garantía del cumplimiento de las políticas, de las normas y de los propósitos institucionales, así como de la información involucrada para hacer más transparente la rendición de cuentas. La sentencia C-103 de 2015 le ratificó al control interno la función de advertencia; sin embargo, a la fecha no se conocen acciones preventivas de importancia por parte de las oficinas de control interno, que hayan evitado el daño al patrimonio público, por lo que es evidente que el actual modelo de control interno, -dado los resultados examinados frente a la corrupción-, continúa en deuda con la sociedad, por su inefectividad.

Por otra parte, la recentralización del control fiscal en la Contraloría General de la República -CGR, no puede considerarse la mejor medida para lograr la eficiencia y efectividad del control fiscal y para la lucha contra la corrupción. El fortalecimiento del nivel territorial de la administración pública y del control a la misma, a partir de una verdadera descentralización, del impulso del control social y garantías de autonomía para tomar decisiones estratégicas en las regiones, constituyen requisito fundamental para la lograr la óptima inversión de los recursos públicos y consecuentemente, la superación de la desigualdad y la pobreza, aspectos centrales en la construcción de una paz estable y duradera.

En una intervención ante los contralores del país, el Auditor General de la República, Carlos Hernán Rodríguez Becerra, se pronunció frente a las tendencias re centralizadoras, así:

(...) Adicionalmente, desde un punto de vista geopolítico, Colombia es el compendio de una gran variedad de culturas y por ende en cada región se configuran diferentes territorialidades, es decir que, a manera de ejemplo, la forma de garantizar el derecho a la seguridad alimentaria, que es un derecho humano universal, no puede ser la misma en Mitú que en Palmira. Lo anterior significa que la institucionalidad debe estar en capacidad de reconocer y respetar la diferencia, la interculturalidad y no caer en el círculo vicioso de la exclusión social, abonando el terreno para la corrupción. Es allí, precisamente, en la territorialidad, en donde cobra valor fundamental, la descentralización y por ello, el papel que juega la Contraloría Territorial es determinante, para garantizar la materialización de un Estado Social de Derecho.

(...) No puede concebirse un control fiscal territorial desde el nivel central del Estado, sin lesionar gravemente el concepto de descentralización concebido por el Constituyente de 1991.

La descentralización administrativa, en palabras del Doctor Libardo Rodríguez, exconsejero de Estado, es "la facultad que se otorga a las diferentes entidades públicas del Estado para gobernarse por sí mismas, mediante la radicación de funciones en sus manos para que las 
ejerzan autónomamente".

Por lo anterior, no cabe duda que intentar eliminar las Contralorías Territoriales que hoy existen en el país para trasladarle esas funciones a la Contraloría General de la República, no solo es incongruente con la descentralización administrativa, sino que riñe con el espíritu mismo de nuestra Constitución, en especial con el postulado fundamental contenido el artículo $1^{\circ}$ que desarrolla uno de los principios de la Carta Política: "Colombia es un Estado social de derecho, organizado en forma de República unitaria, descentralizada, con autonomía de sus entidades territoriales (...)

Y continuó el señor Auditor a los contralores territoriales:

No obstante, se observa una fuerte tendencia nacional hacia el logro de este cometido de eliminación de las contralorías territoriales. Así se desprende de las líneas generales de política pública elaboradas por el DNP. Un ejemplo de ello lo constituye el documento CONPES 167 de 2013, citado al inicio de mi intervención, que identifica una serie de debilidades en el Control Fiscal Territorial, entre las que se encuentran:

- La falta de resultados efectivos en el proceso auditor

- El incumplimiento de obligaciones fiscales

- Y la no revisión de las cuentas recibidas

Esto nos lleva a preguntarse si ¿Acabando con las contralorías territoriales se soluciona el problema del control fiscal en el país y se acaba con la corrupción administrativa? Es claro que la respuesta a este cuestionamiento es negativa, por cuanto nada garantiza que, con la centralización del Control Fiscal territorial en la CGR o cualquier otro ente, se logren mejores resultados en Control Fiscal y en la gestión pública territorial.

Si la preocupación radica en los niveles de corrupción vigentes hoy en el país, la solución no puede ser la eliminación de las Contralorías Territoriales, pues esa corrupción ha alcanzado las proporciones señaladas, aún con la existencia de la Contraloría General de la República en lo nacional y en lo territorial con vigencia de sus controles excepcionales (preferente y prevalente).".

En ese contexto, surge la pregunta: ¿Qué hacer? Varios estudios propiciados por la academia, la Auditoría General de la República, organismos multilaterales como el Banco Mundial y los mismos organismos de control fiscal, así como las deliberaciones y conclusiones de diversos foros y eventos técnicos, han dado cuenta de la impostergable decisión que han de tomar las instancias correspondientes frente al necesario fortalecimiento del control fiscal en Colombia, particularmente, en lo atinente al control fiscal territorial como elemento fundamental de la descentralización y de la democracia local.

El presente documento, resume las principales propuestas que ha venido acopiando, sistematizando y propiciando la Auditoría General de la República como organismo de control fiscal de segundo nivel, en su condición de auditora de los contralores.

De manera que las siguientes propuestas de acción, basadas en diagnósticos recurrentes pero actualizados, nos permiten dar respuesta suficientemente autorizada y documentada a los 


\section{OPPCF}

interrogantes del CONPES 167 de 2013.

\subsection{DIAGNÓSTICO Y PROPUESTAS DE SOLUCIÓN}

\subsubsection{Corregir la estructura difusa del control fiscal}

Una primera mirada sobre el modelo de control fiscal en nuestro país, advierte sobre la “Difusa estructura del Sistema de Control Nacional". (AGR-Banco Mundial, 2011)

Aparentemente, no resulta razonable la existencia de 66 contralorías, a saber: Contraloría General de la República, 32 contralorías departamentales y 33 contralorías distritales y municipales. Además, como organismos de control fiscal de segundo nivel: la Auditoría General de la República y la Auditoría Fiscal ante la Contraloría de Bogotá, D.C.

Lo realmente no razonable, es la muy precaria articulación entre esa frondosa institucionalidad del control fiscal que inhibe trabajar con economías de escala y conduce a unos resultados dispersos en sus procesos misionales de auditoría y de resarcimiento efectivo del daño causado al patrimonio público.

El problema no es la existencia de contralorías en el nivel territorial. El problema radica en la política de no tomar medidas de fondo para permitir su articulación y fortalecimiento. Las dificultades para establecer un efectivo engranaje institucional, que haga práctico, seguro y eficiente el control fiscal desde y hacia los territorios, provienen lamentablemente, de algunos niveles de decisión del gobierno y de la misma CGR, que propician su estrangulamiento y por ende el riesgo de su desaparición.

Contrario a esas intenciones de propiciar la eliminación el control fiscal territorial, el primer llamado de la mayoría de propuestas de fortalecimiento apunta a la necesidad de crear formalmente un verdadero Sistema Nacional Territorial de Control Fiscal, con atribuciones para proponer políticas públicas cohesionadoras en las materias de su competencia; definir planes y programas de cobertura nacional, regional y local de mediano y largo plazo frente a la vigilancia y control a los recursos públicos; consensuar los distintos niveles de participación de las contralorías en dichos planes y programas y hacer viables los principios de complementariedad y subsidiariedad cuando corresponda.

Además de dirigir la capacitación, el desarrollo informático y proponer la distribución de cargas y beneficios generados por la operación de dicho sistema, deberá determinarse claramente un nuevo esquema de relaciones interinstitucionales en términos de roles, recursos, responsabilidades y competencias de todos los componentes del sistema: Contraloría General, contralorías departamentales, contralorías distritales y municipales, Auditoría General de la 
República, Auditoría Fiscal ante la Contraloría de Bogotá D.C., y el organismo representativo de las oficinas de control interno. Componente fundamental del nuevo sistema serán las organizaciones representativas del control social. (Restrepo, Araujo y Tuta, 2010. p89 y 90; AGR-Banco Mundial, 2011. p.82).

En este contexto, una eficiente estructura del control fiscal tiene que ver con las medidas que deberán tomarse para superar la fractura del control fiscal externo con el control fiscal interno y establecer nuevas relaciones entre estos dos niveles del control, tal y como se examina en otro acápite del presente estudio. Así mismo, tiene que ver con la reclamada autonomía presupuestal, la independencia política de los contralores frente a sus vigilados y la carrera administrativa especial para los servidores públicos de las contralorías, temas que están bajo la responsabilidad de otras autoridades en el plan de acción del CONPES 167.

La Auditoría General de la República, asume el compromiso de elaborar de manera participativa la propuesta normativa, durante el primer semestre de 2018.

\section{2.2. Otorgar la función preventiva al control fiscal}

El debate sobre la efectividad del control fiscal ha sido intenso. Las contralorías, incluida la Contraloría General de la República, fungen como notarios que solamente pueden dar fe pública del daño patrimonial causado, sin que puedan evitarlo. Y tampoco han logrado recuperar los billonarios recursos desfalcados al erario porque una vez despojada la sociedad de sus recursos, ese daño al patrimonio público deviene en irreparable.

Una buena parte de las contralorías departamentales y municipales con los recursos presupuestales prácticamente congelados desde el año 2000 por las decisiones de la ley 617 de ese año, tienen graves limitaciones tecnológicas y de talento humano que no les ha permitido abordar el control de manera eficiente, oportuna y con la cobertura y calidad requerida.

Asílas cosas, hoy el control es demasiado posterior, demasiado selectivo, y, por tanto, demasiado permisivo, y hasta ahora, han fracasado todos los intentos de reforma para fortalecerlo; por ejemplo, el de otorgarle funciones preventivas que no constituyan control previo, sino control inmediato o en tiempo real.

Para ilustrar la importancia de los instrumentos preventivos, basta analizar las intervenciones de la ex contralora Sandra Morelli y del actual contralor Edgardo Maya cuando explicaban la ausencia de control fiscal oportuno y efectivo en los sucesos de la Refinería de Cartagena: El organismo de control, no tenía, ni tiene como intervenir, o siquiera advertir sobre las irregularidades en curso, porque la ley no se lo permite a la contraloría. (Semana en vivo, 2016)

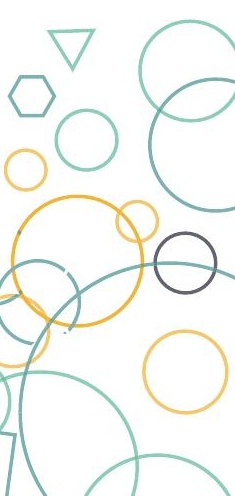




\section{OPPCF}

La función de advertencia, como un instrumento del control posterior pero inmediato que tenían las contralorías para prevenir posible daño al patrimonio público, fue declarada inconstitucional mediante sentencia C-103/2015 de la Corte Constitucional.

En consecuencia, debido a que nuestra Carta Política no dispone de un enfoque preventivo frente al posible menoscabo del patrimonio público, el tema del control y su necesario reenfoque merece un debate creativo, a fin de proponer ideas e instrumentos que conlleven a la toma de decisiones de política pública que permitan disponer, entre otras de la facultad de "advertencia" o de una figura similar, o de comunicar "alertas tempranas" como producto del ejercicio oportuno y efectivo del análisis de riesgos que realizan las contralorías en desarrollo del control fiscal posterior pero inmediato.

La nueva legislación al respecto, deberá disponer medidas preventivas, tales como solicitar dentro del ámbito de sus competencias la suspensión de procedimientos administrativos, actos, contratos o su ejecución, para que cesen los efectos y se eviten los perjuicios, cuando existan indicios graves que permitan inferir la vulneración inminente del patrimonio público.

Esta medida solo podría ser decretada por el respectivo contralor, quien no podrá delegar su ejercicio, y la misma conservará su vigencia hasta un plazo máximo de dos meses, término durante el cual el organismo de control deberá promover las acciones judiciales pertinentes.

Igual que en el punto anterior, relativo a la estructura del control fiscal, la Auditoría General de la República, asume el compromiso de elaborar de manera participativa la propuesta normativa referida a la facultad preventiva del control fiscal, tema que desarrollará y culminará durante el primer semestre de 2018.

\section{2.3. Medidas para mejorar el resarcimiento del daño al patrimonio público}

Axiomático es que, medir en términos de eficiencia y eficacia la gestión de las contralorías territoriales con base en los resultados de recuperación de activos, o recaudo que es lo mismo, no es ni técnica ni justamente adecuado. Aseverar que su gestión se concreta al recaudo del daño patrimonial, es desconocer la naturaleza, función y operación del control fiscal.

Concluir costo beneficio, comparando simplemente lo que cuesta una contraloría (presupuesto) con lo que recauda, es un desacierto cuyos resultados han sido siempre, y seguirán siendo, desafortunados y desalentadores; y un errado y débil argumento de quienes promueven las intenciones de centralización del control fiscal.

Para identificar estrategias y desarrollar herramientas que sirvan para luchar contra la impunidad en actos de corrupción, y en particular los que implican detrimento patrimonial al 
Estado, hay que entender necesariamente, que la gestión de control fiscal de las contralorías territoriales es, y debe medirse como un todo, de manera integral, incluyendo, como se explica adelante, los beneficios cuantificables y no cuantificables del ejercicio de control fiscal de las contralorías territoriales, que no siempre implican recaudo, sino que trascienden esa noción.

Es en este contexto y teniendo en cuenta que la problemática del control fiscal territorial ha sido históricamente identificada con los pobres e inefectivos resultados de los procesos de responsabilidad fiscal y de cobro coactivo; cuya normatividad hace casi que nugatoria la posibilidad de resarcimiento del daño, debilitando aún más el proceso; se proponen en este documento, medidas concretas que faciliten y aseguren alcanzar los niveles de eficiencia y eficacia en la recuperación de activos que busca la Estrategia Nacional de la Política Pública Integral Anticorrupción.

\section{- El carácter de juez y parte.}

El doble carácter de investigadores y jueces de las contralorías territoriales desnaturaliza su función técnica de vigilancia; y hace que converja en un mismo organismo, las funciones de recolección de pruebas, denuncia, instrucción de procesos, fallos y cobro de dineros ${ }^{72}$, restándole imparcialidad y objetividad; sin que se garantice el recurso de alzada ante organismos diferentes al que identificó el hallazgo. (Rendón, 2001; AGR Sindéresis, 2002; Ochoa y Charris, 2013).

(...) Otras situaciones adversas se reflejan en la debilidad de las garantías de defensa de los implicados en los procesos de responsabilidad fiscal, en una situación de incertidumbre y desconcierto en la sociedad, a partir de casos específicos analizados o nulidades que produce la justicia a los fallos de las contralorías. Para el individuo, el control es sancionatorio y punitivo, no es reparador ni preventivo; es amenazante de sus derechos humanos fundamentales como la dignidad humana, la libertad de empresa, el buen nombre, el derecho al trabajo y otros derechos. Predomina la desconfianza mutua en los organismos de control hacia los actores de la gestión pública y la gestión contractual, que no comprenden los escenarios de incertidumbre y dificultad para tales gestores fiscales. En reciprocidad, los sujetos vigilados tampoco confían en tales organismos. (...) (Gómez y Céspedes, 2017)

\section{- La naturaleza administrativa y cuasi jurisdiccional de las contralorías.}

En el trámite de los procesos de responsabilidad fiscal y de cobro coactivo, las contralorías fungen como una jurisdicción más, deben disponer de una infraestructura y recursos profesionales ${ }^{73}$ necesarios para judicializar también los hallazgos fiscales que identifican, desdibujando su papel estrictamente técnico y restándole eficacia en la vigilancia de la gestión fiscal que le corresponde a los órganos de control fiscal (Naranjo, 2007). Ese ejercicio cuasi jurisdiccional implica, lo que se puede calificarse como desgaste operativo de las contralorías, y ha exigido que tales órganos de control hagan ingentes esfuerzos económicos para la mejora y automatización de los procesos de responsabilidad fiscal y de cobro coactivo, esfuerzos que hoy no solo están dispersos, sino que no están estandarizados y el nivel de madurez de buena parte de ellos sigue siendo muy bajo (MINTIC Gobierno en

72 Afirmación que es más evidente en las contralorías territoriales con pocos funcionarios, que exige que algunos tengan ese carácter dual reprochado.

73 El número de funcionarios de las contralorías territoriales - sin contar la de Bogotá- destinados a adelantar los procesos fiscales para la vigencia 2016 fue de 380 .

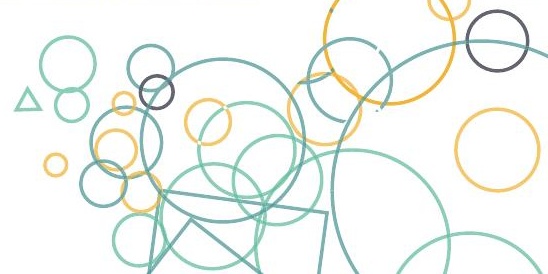


Línea-AGR, 2012, p.22).

Sobre esa función, se encontró que: “En muchos países no se encomiendan a las contralorías funciones sancionatorias; su labor se limita a constatar la existencia de procedimientos, a evaluar los resultados, pero toda sospecha de manejos inadecuados o negligentes debe ser remitida a autoridades judiciales". (Ochoa y Charris, 2013) Negrilla fuera del texto.

\section{- La ocurrencia frecuente de prescripción de la responsabilidad fiscal, de la caducidad de la acción fiscal y la baja recuperación de cartera.}

En buena parte de los procesos fiscales, por impericia, inactividad, inexperiencia, falta de recursos físicos, humanos, técnicos, de infraestructura, oportunidad o debilidades de autocontrol, se obliga a la declaratoria de la caducidad de la acción fiscal ${ }^{74}$ porque no se abrió proceso dentro de los cinco años siguientes a la ocurrencia del daño investigado; o nulidades procesales que demoran el trámite de los procesos; hasta el punto tal que llegan a imposibilitar totalmente el resarcimiento del daño patrimonial en unos casos, o a obtener una baja recuperación de cartera en otros; o a la declaratoria de ocurrencia de la prescripción de la responsabilidad fiscal ${ }^{75}$, porque por dilación, falta de pericia, herramientas o recursos, no fue posible fallar de fondo dentro de los cinco años siguientes al auto de apertura del proceso.

Estudios muestran que los resultados de este proceso, para cuales la vía judicial está abierta, no son satisfactorios. Los procesos duran años (hay cifras que hablan de un promedio de trece años), con pocos éxitos en cuanto a sanciones y/o la recuperación de recursos malversados o de la reparación del daño económico causado. Desde el punto de vista de la política anticorrupción el proceso tampoco es satisfactorio, porque muestra que finalmente el riesgo para ser sancionado y responsabilizado por un acto corrupto, después de un proceso largo, es mínimo para un funcionario mal intencionado. (López, 2006)

\section{- El proceso de responsabilidad fiscal es permisivo.}

Con la sentencia C-619 de 8 de agosto de 2002, la Corte Constitucional impuso al funcionario instructor del proceso de responsabilidad fiscal la necesidad de probar culpa grave para responsabilidad fiscal, en lugar de culpa leve que se equipara a la negligencia, tal como estaba previsto originariamente por el legislador al expedir la Ley 610 de 2000. Esta decisión de la Corte trajo como resultado un obstáculo que impide la recuperación del patrimonio público calificado con culpa leve y en lugar de atacar la corrupción, es un anuncio de tolerancia frente a la impunidad. (Ordóñez, 2007).

Consecuencia de lo afirmado es, que el alto número de autos de archivo y de fallos sin responsabilidad fiscal, cuya cuantía se contabiliza en las estadísticas como presunto daño patrimonial investigado, corresponde en muy buena parte a casos en los que se verificó la existencia de un daño patrimonial al Estado, y en los que por alguna razón no se logró probar la culpa grave de los gestores fiscales. Incluso, están en ese presupuesto los

74 Según lo reportado en la rendición de cuentas realizada por las contralorías a la Auditoría General de la República, entre 2012 y 2016 se archivaron por caducidad de la acción fiscal 233 procesos de responsabilidad fiscal tramitados por procedimiento ordinario, y un valor total de 176.943.654.010 pesos.

Según lo reportado en la rendición de cuentas realizada por las contralorías a la Auditoría General de la República, entre 2012 y 2016 se archivaron por prescripción de la responsabilidad fiscal 662 procesos de responsabilidad fiscal tramitados por procedimiento ordinario, y un valor total de 186.604.913.276 pesos. 
procesos que se abrieron con base en deficiencias administrativas, del error consecuencia del descuido, la ignorancia, la negligencia, la indolencia o el desgreño de los gestores fiscales, que existiendo, no fueron suficientes para enmarcarse en el grado de culpa grave que exige la referida sentencia (Gómez y Ordóñez, 2010).

En ese contexto general, se propone como medida para obtener una eficiente y eficaz recuperación de daño patrimonial causado al erario, la de liberar a las contralorías territoriales de la función de adelantar y tramitar hasta su culminación los procesos de responsabilidad fiscal y de cobro coactivo, y radicarla en una jurisdicción real, como la de lo Contencioso Administrativo, adicionando los procesos de responsabilidad fiscal y jurisdicción coactiva en los listados del artículo 104 de la Ley 1437 de 2011, eliminando la simbiosis innecesaria entre dos funciones perfectamente diferenciables, una de las cuales es más propia de la Rama Judicial, superando una de las más grandes atrofias del sistema de control fiscal (AGR Sindéresis, 2002), con lo cual, las contralorías ganarían fortaleza como órganos de auditoría pública (Naranjo, 2007).

Con la implementación de ésta medida, se propendería por un restablecimiento real y oportuno del daño patrimonial causado al patrimonio público, con fallos jurídicos adecuados, minimizando los riesgos de caducidad, de prescripción, de nulidades y dilaciones procesales, además de evitar que los responsables fiscales se insolventen corruptamente para evadir las consecuencias de su indebida y dañina gestión. En este escenario, se prevé que los fallos se multiplicarían, se garantizaría aún más el derecho defensa y la segunda instancia, se decretarían y ejecutarían medidas cautelares por quien tiene la infraestructura y las herramientas para hacerlo, y se evitaría tener que remitir, de todas formas, a la jurisdicción de lo contencioso administrativo por el uso de medios de control como el de nulidad y restablecimiento del derecho, los fallos con responsabilidad fiscal ejecutoriados, que siempre son demandados ante esa jurisdicción, haciendo menos complejo y gravoso el proceso de responsabilidad.

Todo lo anterior conllevaría en consecuencia, a lograr una efectiva recuperación de los recursos públicos, y disminuir el nivel de impunidad de los gestores fiscales que con su acción u omisión lo dañan. La mencionada propuesta no es nueva, viene exponiéndose en distintos escenarios y por distintos estudiosos del tema, entre ellos (Suarez, 2001), (Rendón, 2001) (Ochoa y Charris, 2003) (López, 2006) (Ossa, 2006) (Gómez y Céspedes, 2017).

Ahora bien, como propuesta alternativa, está la de fortalecer el proceso de responsabilidad fiscal eliminando la exigencia de culpa grave para responsabilizar fiscalmente; aumentar las presunciones del Estatuto Anticorrupción; hacer que la investigación de bienes y el decreto

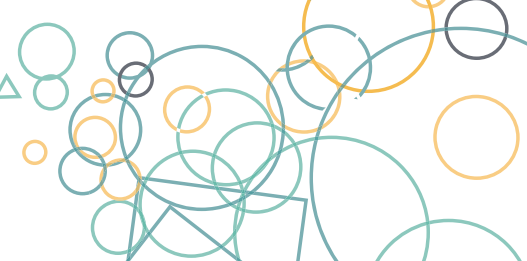




\section{OPPCF}

de medidas cautelares no sea facultativo del operador jurídico, sino obligatorio desde que se suscribe el auto de apertura en procesos de responsabilidad tramitados por el procedimiento ordinario, y el auto de apertura e imputación en los procesos tramitados por procedimiento verbal; establecer convenios con entidades internacionales y nacionales para la identificación y ubicación de bienes y propiedades de los investigados, como por ejemplo las Oficinas de Registro, el Instituto Geográfico Agustín Codazzi, las Oficinas de Catastro autónomas, el Fondo Nacional del Ahorro, Ecopetrol, entre otras instancias, que faciliten acceder a bases de datos nacionales sobre la información de bienes de los presuntos responsables, evitando el desgaste que implica para las contralorías territoriales. tantos trámites engorrosos de oficiar a todo el país, con las demoras que esto conlleva, lo que afecta la oportunidad del decreto y práctica de medidas cautelares (MINTIC Gobierno en Línea-AGR, 2012, p.22).

Finalmente, reglamentar la remisibilidad de deudas fiscales -como ocurre con las tributarias-, para que las contralorías territoriales y en general los órganos de control fiscal puedan dejar de cargar grandes sumas de fallos con responsabilidad fiscal y resoluciones sancionatorias, que son incobrables por la práctica perversa de los gestores fiscales que se han insolventado para evitar pagar el daño patrimonial causado al Estado, lo que ha constituido durante años, una carga pesada que afecta en gran parte las estadísticas de recaudo de las contralorías, y que deberán seguir cargando indefinidamente, mientras no haya orientación, reglamentación y unidad de criterio a nivel nacional para eliminar de la cartera por cobrar, lo realmente incobrable.

\section{2.4. Garantizar la autonomía de los órganos de control fiscal territorial}

El mandato Superior en su artículo 267 determina que la Contraloría es una entidad de carácter técnico, con autonomía administrativa y presupuestal. A su vez, la INTOSAI (Organización Internacional de las Entidades Fiscalizadoras Superiores -EFS), en su Declaración de México -mayo de 2007- estableció:

Los principios básicos de la independencia de las EFS son las siguientes:

1. La existencia de un marco constitucional, reglamentario o legal apropiado y eficaz, así como de disposiciones para la aplicación de facto de dicho marco

2. La independencia de la autoridad superior de la EFS, y de los "miembros" (para el caso de instituciones colegiadas), incluyendo la seguridad en el cargo y la inmunidad legal en el cumplimiento normal de sus obligaciones.

3. Un mandato suficientemente amplio y facultades plenamente discrecionales en el cumplimiento de las funciones de la EFS

4. Acceso irrestricto a la información 
5. El derecho y la obligación de informar sobre su trabajo

6. Libertad de decidir el contenido y la oportunidad (momento) de sus informes de auditoría, al igual que sobre su publicación y divulgación

7. La existencia de mecanismos eficaces de seguimiento de las recomendaciones de la EFS

8. Autonomía financiera y gerencial/administrativa, al igual que disponibilidad de recursos humanos, materiales y económicos apropiados

Las disposiciones para la aplicación de estos principios sirven para ilustrarlos y se consideran como el ideal para una EFS independiente. (INTOSAI, 2007)

En nuestro país, no ha sido posible garantizar una verdadera autonomía presupuestal ni la necesaria independencia de los organismos de control fiscal, frente a sus vigilados. En efecto, uno de los problemas que afecta la autonomía y la independencia del control fiscal consiste en que los gobernantes a vigilar en el nivel territorial son elegidos para un período de cuatro años el último domingo del mes de octubre y se posesionan el $1^{\circ}$ de enero del año siguiente.

Durante el tiempo que transcurre a partir de la elección del gobernante, se realiza la campaña de los aspirantes a ocupar los cargos de contralor departamental, distrital o municipal, en la respectiva entidad territorial, campaña en la que resulta inevitable la injerencia de los gobernantes elegidos, que serán objeto de control fiscal por el contralor a elegir por las asambleas y concejos.

Todo ello a pesar del mandato constitucional ${ }^{76}$ que ordena sujetar dicha elección a una convocatoria pública "conforme a la ley" y sometida a principios de transparencia, objetividad, publicidad, participación ciudadana y equidad de género. La reforma constitucional es de 2015 y la ley que regula la convocatoria pública no ha sido expedida.

El procedimiento de convocatoria pública no parece resolver el problema planteado frente a las garantías de transparencia, objetividad e independencia, dado que los puntajes otorgados en las entrevistas por las corporaciones públicas pueden primar frente a los resultados de los exámenes sobre conocimientos técnicos, experiencia y otras variables para medir la idoneidad de los elegidos. De manera que, sigue primando la posible injerencia de los gobernantes en la elección de sus controladores, así como los posibles intereses indebidos de diputados y concejales.

De manera que se impone la adopción de medidas más efectivas y asertivas en el proceso de selección y elección de quienes tendrán a su cargo la vigilancia de la gestión fiscal en los

76 Acto Legislativo 2 de 2015, que modificó el artículo 272 de la Constitución Política 


\section{OPPCF}

departamentos, distritos y municipios, que incluya modificar la forma y requisitos para la designación de los contralores y los cuerpos directivos de las contralorías.

El procedimiento idóneo es el concurso de méritos, con exigencias precisas de experiencia sobre control fiscal demostrable y altos niveles de probidad para quienes aspiren a ocupar dichos cargos, entre otros.

Adicionalmente, los contralores serán escogidos para períodos de cuatro años, que deberán iniciar a la mitad del período del gobernante de turno y terminar a la mitad del siguiente, sin que puedan ser reelegidos.

De manera complementaria, debe resolverse el grave problema de recursos presupuestales de las contralorías, como se explica líneas adelante. Así las cosas, se posibilita la construcción de nuevas relaciones de independencia y autonomía frente a los vigilados.

La tarea de "Presentar un proyecto de ley para crear la carrera administrativa de las contralorías territoriales y modificar la forma de elección de los contralores territoriales, para garantizar la transparencia de dichos procesos", contenida en el plan de acción del Documento CONPES 167 , a cargo del Ministerio del Interior, es fundamental para consolidar una estructura eficiente y efectiva del control fiscal.

\subsubsection{Un nuevo modo de cálculo presupuestal para las contralorías territoriales}

Las normas que rigen los presupuestos de los organismos de control en los territorios son muy rígidas. Fueron diseñadas hace 17 años para superar una situación de crisis fiscal en los municipios y departamentos, pero han permanecido invariables desde entonces, a pesar de haberse superado las causas que originaron esas medidas restrictivas. Según la Ley 617 de 2000 , las medidas de ajuste fueron transitorias para todos los organismos del nivel ejecutivo, pero no así, para los organismos de control fiscal, generando una nefasta asimetría entre las capacidades de gestión de los vigilados frente a la de los vigilantes en claro detrimento de éstos últimos. Y es a la postre, la sociedad -en los territorios- la que ha visto afectada su capacidad de controlar a los gobernantes. Pareciera que, de manera deliberada, se debilitara el ejercicio del control fiscal para facilitar el accionar de la des-administración. Adicionalmente, las diferencias presupuestales entre las contralorías y su capacidad de gestión son muy diferentes y en la actualidad no existen políticas para su fortalecimiento.

Para corregir esta situación, es hora de suprimir aquellos artículos de la Ley 617 de 2000 que ahogan y extinguen paulatinamente el presupuesto de las contralorías, así como derogar el artículo 15 de la Ley 330 de 1996, en cuanto a la prohibición a las contralorías departamentales 
de contratar por prestación de servicios. Resulta imperativo otorgar la posibilidad legal para que las contralorías realicen inversión en tecnología y demás elementos efectivos de modernización institucional para aumentar su capacidad de gestión y de resultados.

Por disposición del artículo 267 constitucional, la Contraloría es una entidad de carácter técnico con autonomía administrativa y presupuestal. En igual sentido, en relación con las contralorías departamentales y municipales el artículo 272 de la Carta Política dispone que corresponde a las asambleas y a los concejos Distritales y Municipales organizar las respectivas contralorías como entidades técnicas dotadas de autonomía administrativa y presupuestal.

En desarrollo de estos preceptos constitucionales, el Legislador, atendiendo el espíritu de las normas constitucionales, estableció en el artículo 54 de la Ley 42 de 1993 lo siguiente:

En ejercicio de la autonomía presupuestal la Contraloría General de la República elaborará cada año su proyecto de presupuesto de gastos o de apropiaciones para ser presentado a la Dirección General de Presupuesto, quien lo incorporará al respectivo proyecto de ley de presupuesto que se someterá a la consideración del Congreso de la República.

Además, la Ley 106 de 1993 en el artículo $4^{\circ}$ dispone que en desarrollo de la autonomía presupuestal la Contraloría General de la República, maneja, administra y fija su presupuesto en concordancia con la Ley Orgánica del Presupuesto.

A nivel territorial, la Ley 136 de 1994 en su artículo 165, señala lo siguiente en relación con el tema:

Los contralores distritales y municipales, tendrán, además de lo establecido en el artículo 272 de la Constitución Política, las siguientes atribuciones: (...) 12. Elaborar el proyecto de presupuesto de la Contraloría y presentarlo al alcalde, dentro de los términos establecidos en esta Ley, para ser incorporadas al proyecto de presupuesto anual de rentas y gastos. El alcalde no podrá modificarlo. (...) Una vez aprobado el presupuesto no podrá ser objeto de traslados por decisión del alcalde.

Por otra parte, la noción de autonomía presupuestal fue aclarada por el Consejo de Estado en concepto de octubre 9 de 1995, de la siguiente manera:

La autonomía presupuestal se manifiesta en la iniciativa de elaboración del proyecto de presupuesto; en la existencia de un mecanismo legal de no reducción de la partida presupuestal y de actualización monetaria de la misma; en la imposibilidad de modificación del proyecto por el alcalde o de realizar traslados administrativos, así como en la capacidad para ordenar el gasto y celebrar contratos en función de la ejecución del respectivo presupuesto.

De lo anterior se concluye:

- Que la autonomía presupuestal de las contralorías territoriales, les permite a estas elaborar en forma independiente el proyecto de presupuesto de rentas y gastos de la respectiva contraloría, con el fin de que éste sea incorporado por parte del alcalde o gobernador, 


\section{OPPCF}

según corresponda, en el proyecto de presupuesto anual del respectivo departamento o municipio.

- Que la autoridad administrativa local, no puede modificar el proyecto de presupuesto presentado por la Contraloría, y no está facultada para realizar modificaciones en el presupuesto, una vez este haya sido aprobado.

Con la expedición de la Ley 617 de 2000 se fijaron límites para los gastos de funcionamiento de las Contralorías Distritales, Municipales y Departamentales, de tal forma que dichos gastos, a partir de la vigencia de la Ley, deberían financiarse con los ingresos corrientes de libre destinación de la correspondiente entidad territorial, esto es, excluyendo renglones importantes como la participación de los municipios en los ingresos corrientes de la Nación de forzosa inversión, los ingresos percibidos en favor de terceros, los recursos del balance, los recursos de cofinanciación, las regalías y compensaciones, las operaciones de crédito público y la sobretasa al ACPM.

Adicionalmente, la ley estableció que a partir del año 2005 los gastos de las contralorías no podrían crecer por encima de la meta de inflación establecida por el Banco de la República.

No cabe duda que esta decisión afectó de manera grave el funcionamiento de los Organismos de Control Fiscal territorial del país y redujo de manera drástica el campo de acción funcional de las contralorías, desconociendo los postulados básicos de la descentralización administrativa consagrados en la Constitución Política, creando un mecanismo perverso de aniquilamiento institucional a partir del decrecimiento real de los presupuestos de estos Organismos de Fiscalización, en relación con el aumento paulatino de los gastos de funcionamiento, en especial en la remuneración de los servicios personales y de nómina, con lo que la autonomía de las entidades territoriales quedó reducida a un mero formalismo y la sostenibilidad del proceso de descentralización no se garantizó.

En efecto, la variación acumulada en el IPC a partir del año 2005 es significativamente menor al aumento mostrado en los salarios y prestaciones sociales de los funcionarios de las contralorías territoriales y en general de los gastos de funcionamiento, situación que ha generado un desequilibrio financiero importante que afecta de manera grave el normal funcionamiento de las contralorías territoriales.

Este desfinanciamiento de tipo presupuestal genera además la imposibilidad real que tienen estos organismos de control de contar con un rubro específico de inversión que les permita adelantar proyectos importantes para la aplicación del Control Fiscal como el desarrollo de 
tecnologías de la información y las comunicaciones, programas avanzados de formación y capacitación de funcionarios, entre otros. De contar con un adecuado financiamiento, se posibilitaría el avance en el diseño y aplicación de nuevos y mejores procedimientos y técnicas de auditoría, como elemento fundamental en lucha contra la corrupción.

Es por ello, que se requiere con urgencia modificar la forma en que se fija en la actualidad, el presupuesto que se destina a las contralorías territoriales, mediante la adopción de una fórmula que permita, tanto la sostenibilidad presupuestal de las mismas, como la actualización monetaria anual de las partidas presupuestarias fijadas, sin que se desborden los gastos de funcionamiento de los organismos de control fiscal territorial.

\section{2.6. Superar la fractura entre el control fiscal interno y el control fiscal externo}

No existe una verdadera complementariedad entre el Sistema de Control Fiscal y el Sistema de Control Interno, principalmente con las oficinas evaluadoras, encargadas de realizar la evaluación y asesoría de manera independiente a los diferentes procesos de las entidades del Estado.

La gran cantidad de hallazgos administrativos que se identifican en las auditorías realizadas por las contralorías, asociados a las debilidades del sistema de control interno de las entidades vigiladas, distraen el verdadero ejercicio de control fiscal y no permiten enfocarlo a la identificación y análisis de riesgos fiscales.

Según lo reportado en la rendición de cuentas realizada por las contralorías a la Auditoría General de la República, en el periodo 2012 - 2016, las contralorías territoriales identificaron en sus informes 166.521 hallazgos administrativos y la Contraloría General de la República, para el mismo periodo, 32.072. Es decir, durante los últimos 5 años, los organismos de control fiscal en Colombia identificaron 198.599 hallazgos de naturaleza administrativa.

En Colombia, los organismos de control fiscal y las Oficinas de Control Interno desempeñan roles diferentes, claramente definidos en la ley. Sin embargo, los dos tienen un propósito común que consiste en garantizar el adecuado uso de los recursos públicos, a través de una administración pública transparente, eficiente, efectiva y económica.

La diferencia entre los dos sistemas, radica en que las contralorías realizan control fiscal posterior y selectivo, mientras que las oficinas de control interno lo hacen de forma previa, concomitante y/o posterior. Al respecto la Corte Constitucional desde la sentencia C-534 de 1993 y en consideración a la atribución del artículo 268 numeral $6^{\circ}$ de la Constitución, ha dicho: 
(...) Al colocarse en cabeza de la administración (sic) la obligación de conceptuar la calidad y eficiencia del control fiscal interno de las entidades y organismos del Estado, como lo prevé la propia Constitución (art. 268 numeral 6o.), se logra una distinción esencial entre los contenidos, fines y responsabilidades propios del control interno, que debe organizarse en las entidades públicas y las del control fiscal externo ejercido por la Contraloría General de la República y las contralorías departamentales, distritales y municipales a nivel territorial.

Se confiere así forma real a la diferenciación entre las tareas administrativas y las de control fiscal, de donde el control interno se entiende como parte del proceso administrativo y corresponde adelantarlo a los administradores; teniendo oportunidades propias en todos los momentos del cumplimiento de la función administrativa, pudiendo serlo previo, concomitante y/o posterior, lo que permite que el funcionario cumpla su función, asumiendo la responsabilidad por sus actuaciones y resultados; sin perjuicio de la independencia de los organismos de control fiscal, no coadministradores, que cumplirán sus funciones de manera posterior y selectiva, sin ocuparse de funciones administrativas distintas de las inherentes a su propia organización (artículo 267 C.N.). Por eso, la Carta atribuye al Contralor General de la República, la facultad de conceptuar sobre la "calidad" y "eficiencia" del control fiscal interno de las entidades y organismos estatales, evaluación que ha sido definida por la ley como el análisis de los sistemas de control interno de las entidades sujetas a la vigilancia, con el fin de determinar la calidad de los mismos, el nivel de confianza que se les puede otorgar y si son eficaces y eficientes en el cumplimiento de sus objetivos (...) (artículo 18 Ley 42 de 1993).

En consecuencia, en materia de control interno se requieren nuevos desarrollos normativos que permitan diseñar mecanismos de coordinación y cooperación, enfocados a fortalecer la vigilancia oportuna de los recursos públicos.

La creación del Sistema de Control Fiscal, debe vincular, como un actor fundamental para su activación, a las Oficinas de Control Interno.

Respecto a la falta de complementariedad entre el control fiscal y el control interno, la AGR, en el documento titulado la Impostergable Reingeniería del Control Fiscal Territorial, señala:

(...) Problemática: Los eslabones de la cadena de valor del control fiscal interno y externo se encuentran fracturados. Ninguno de estos controles ha producido los resultados esperados.

En consecuencia, condición básica para el ejercicio de un control efectivo anticorrupción, la constituye el fortalecimiento de los sistemas de control interno y externo de las entidades vigiladas y de las propias contralorías.

El fortalecimiento, comienza por la forma de provisión de los responsables de las oficinas coordinadoras o evaluadoras, de modo que éstos no deban sus lealtades a los nominadores de cada entidad, sino que su independencia sea garantizada y obedezca a un ingreso por méritos, con estabilidad y período determinados. Este tema fue resuelto parcialmente por el Estatuto Anticorrupción, al determinar que en el nivel central del gobierno, serán el Presidente, los alcaldes y gobernadores quienes seleccionarán por méritos a los jefes de las oficinas de control interno de sus respectivas jurisdicciones. Pero quedó pendiente resolver esos nombramientos en los demás organismos de las demás ramas del poder público y en los mismos organismos de control.

Igualmente, el fortalecimiento del sistema de control, tanto interno como externo, implica otorgar mayores herramientas y autonomía a las oficinas coordinadoras o evaluadoras de control interno, para realizar control preventivo, sin que ello implique autorización alguna 
para validar actuaciones, actividades, operaciones o procesos. El control interno, en esencia, tiene funciones preventivas, que deben ejercerse con independencia e imparcialidad y con posibilidades legales de comunicar advertencias cuando se vislumbren riesgos de pérdida de patrimonio público y también, a nuestro juicio, los jefes de las oficinas coordinadoras deben disponer de capacidad legal para aplicar sanciones (...). (Peláez, Tuta y Gutiérrez, 2013, p.156)

Adicionalmente, la Corte Constitucional en Sentencia C-103 de 2015, declaró inexequible el numeral $7^{\circ}$ del artículo $5^{\circ}$ del Decreto 267 de 2000, en lo relacionado con la función de advertencia, señalando:

(...) En definitiva, de acuerdo con la jurisprudencia de esta Corporación, una de las manifestaciones del carácter amplio e integral del modelo constitucional de vigilancia fiscal de los recursos públicos la constituye la coexistencia de dos niveles de control: el primero, constituido por los mecanismos de control interno, de naturaleza previa y administrativa; el segundo nivel corresponde al control fiscal externo, de carácter posterior y selectivo, que compete realizar a una entidad autónoma e independiente como es la Contraloría, y cuya efectividad depende de su adecuada articulación con el primer nivel de control (...).

\subsubsection{Desarrollo de la carrera administrativa especial en las contralorías territoriales}

Mediante Sentencia C-073 de 2006, la Corte Constitucional fijó el alcance de los artículos 268-10 y 272 de la Carta Política y concluyó que el régimen de carrera administrativa en las contralorías es de carácter especial por disposición del Constituyente. A la fecha, el Congreso de la República no ha expedido las normas que desarrollen el régimen especial de carrera administrativa aplicable a las contralorías territoriales.

La Comisión Nacional del Servicio Civil en cumplimiento del parágrafo 2 del artículo 3 de la Ley 909 de 2004, aplicó en vigencias anteriores, de manera transitoria, el régimen general de carrera y desarrolló los concursos de carrera administrativa para las contralorías territoriales.

Según la cuenta rendida a la AGR, por las contralorías territoriales, al cierre de la vigencia 2016, estas contaban en sus plantas de personal con un total de 3182 servidores públicos, de los cuales: 62 (2\%) son funcionarios de periodo, 718 (22\%) son de libre nombramiento y remoción, 1974 (62\%) son de carrera administrativa, 402 (13\%) son provisionales y 26 (1\%) figuran como supernumerarios.

En consecuencia, es imperativo que el Congreso de la República expida las normas que desarrollen el régimen de carrera administrativa especial de las contralorías territoriales.

Los procesos de selección de los funcionarios que conforman el Sistema de Control Fiscal, principalmente quienes asumen funciones misionales, deben contar con criterios diferentes a los del régimen general de carrera, para demostrar que objetivamente cumplen y cuentan con las competencias requeridas para ejercer funciones especializadas en control fiscal. 
Se propone que los concursos de carrera administrativa para los servidores públicos de las contralorías territoriales, incluyan requisitos que exijan altos estándares en experiencia relacionada, niveles de probidad demostrables y la realización de cursos-concursos, similares a los que hoy se aplican en la Rama Judicial.

Respecto al tema, la AGR, ha expresado que:

(...) 1. Dentro del proceso de reingeniería del control fiscal, liderado por la Auditoría General de la República, en coordinación con los diferentes sectores interesados, (trabajadores, contralores, ciudadanía, gobierno), es fundamental contar con un sistema de vinculación de personal que garantice, por una parte, el mayor grado de idoneidad en el personal vinculado, y por otro, el reconocimiento de todas las garantías y prerrogativas en pro del bienestar de los trabajadores.

2. La carrera administrativa se constituye en el mecanismo más idóneo en la consecución y aplicación de los principios de la función administrativa, particularmente, en términos de excelencia en el desempeño de quienes desarrollen la labor de vigilancia fiscal.

3. Dado que el tema tratado tiene vocación de reserva legal, es necesaria la presentación de un proyecto de ley, en el que se vean claramente las bondades y beneficios de aplicar un sistema de carrera administrativa, eminentemente técnico, (Contraloría General de la República).

4. Para el efecto, es preciso promover el diseño y elaboración de un documento bajo los parámetros del consenso entre los diferentes actores, de manera que no solamente se esté contribuyendo al mejoramiento continuo en el ejercicio de la función administrativa, sino que, sea reconocida en su integridad, y con todas las garantías, la labor de quienes participan desde diferentes escenarios en el desarrollo del control fiscal (...). (Peláez, Tuta, García, 2013, p.153)

Como se señaló líneas atrás, esta tarea de "Presentar un proyecto de ley para crear la carrera administrativa de las contralorías territoriales y modificar la forma de elección de los contralores territoriales, para garantizar la transparencia de dichos procesos", contenida en el plan de acción del Documento CONPES 167, a cargo del Ministerio del Interior, es fundamental para consolidar una estructura eficiente y efectiva del control fiscal.

\subsubsection{Fortalecer la capacidad sancionatoria de las contralorías territoriales y de la AGR.}

Dada la frecuente ocurrencia de situaciones irregulares de forma reiterada, relacionadas con las cuentas e informes rendidos por los sujetos vigilados, la práctica ha demostrado la necesidad de ampliar las causales establecidas en los artículos 100 y 101 de la ley 42 de 1993 y otorgarle a los organismos de control fiscal, la competencia para sancionar aspectos que, por no tener hoy consecuencias sancionatorias, se han convertido en un resultado frecuente del ejercicio de auditoría, generando desinterés por parte de los sujetos vigilados, lo cual le resta contundencia a la labor del control fiscal, tales como: 
- El no fenecimiento de una cuenta.

- La reiteración de conceptos no favorables como producto de la evaluación de la calidad y eficiencia del control fiscal interno en la entidad vigilada.

- Obtener estados contables con dictamen de no razonabilidad o con abstención de opinión.

Sobre este punto:

“(...) La Auditoría General de la República considera conveniente incluir dentro de las causales de sanción establecidas por la ley 42 de 1993, el no fenecimiento de una cuenta y, además, el impedimento legal del responsable, para hacer parte de otra entidad pública, mientras persista la no aprobación. Igualmente, solicitamos incluir como causal de sanción la reiteración de conceptos no favorables como producto de la evaluación de la calidad y eficiencia del control fiscal interno en la entidad vigilada. (...) El incumplimiento parcial o total de los compromisos incluidos en los planes de mejoramiento, será causal de acciones sancionatorias por parte de los organismos de control fiscal. (...)" (Peláez, Tuta, García, 2013)

\subsubsection{La medición de resultados y los beneficios del control fiscal}

El Plan Estratégico de la Organización Internacional de Entidades Fiscalizadoras Superiores INTOSAI- que culminó en 2016, incluyó seis prioridades estratégicas, dentro de las cuales una se relaciona directamente con los beneficios, así:

- Ayudar a asegurar la independencia de las Entidades Fiscalizadoras Superiores - EFS

- Implementación de estándares Internacionales para Instituciones Fiscalizadoras Superiores ISSAI (s)

- Fortalecer la creación de capacidades de las EFS

- Demostrar el Valor y Beneficios de las EFS

- Promover la lucha contra la corrupción

- Mejorar las comunicaciones de la INTOSAI

A propósito, en el año 2010 en los Acuerdos de Johannesburgo, la INTOSAI afirmó:

(...) Las Entidades Fiscalizadoras Superiores fungen como importantes pilares de sus respectivos sistemas democráticos nacionales y juegan un rol fundamental en el mejoramiento del desempeño del sector público, destacando la importancia de los principios de buena gobernanza, transparencia y responsabilidad. Teniendo en cuenta el creciente interés de partes interesadas -internas y externas- así como, la también creciente gama de servicios de auditoría proporcionados por las EFS; la INTOSAI reconoce la necesidad progresiva de demostrar los valores y beneficios que generan las EFS.

(...) El objetivo general de las auditorías independientes es, por lo tanto, generar una diferencia en las vidas de los ciudadanos, al contribuir a la confianza, la eficiencia y la efectividad. EFS independientes y efectivas, son precondición necesaria para la democracia. Esto implica que el mandato de un auditor independiente en el sector público va más allá de la tradicional definición de la auditoría externa, porque trata también con temas de interés público - el interés de los ciudadanos -. 
(...) En nuestro país, el artículo 129 de la ley 1474 de 2011, Estatuto Anticorrupción, determinó como uno de los criterios orientadores de la planeación estratégica de las contralorías territoriales la "Medición permanente de los resultados e impactos producidos por el ejercicio de la función de control fiscal".

Acorde con lo afirmado, y con el texto del artículo 127 de la Ley 1474 de 2011:

La AGR constatará la medición efectuada por las Contralorías de los beneficios generados por el ejercicio de su función, para lo cual tendrá en cuenta que se trate de acciones evidenciadas debidamente comprobadas, que correspondan al seguimiento de acciones establecidas en planes de mejoramiento o que sean producto de observaciones, hallazgos, pronunciamientos o advertencias efectuados por la contraloría, que sean cuantificables o cualificables y que exista una relación directa entre la acción de mejoramiento y el beneficio.

A las contralorías las reconocen los ciudadanos fundamentalmente por los resultados de su gestión y por la efectividad de su trabajo.

Todos los procesos misionales de las contralorías deben medirse, no solamente en términos de la gestión realizada, sino principalmente, por los resultados y efectos de la labor integral del control fiscal. Para esos efectos, la Contraloría General de la República ha diseñado y aplica una metodología para el reporte de los beneficios del control fiscal. A su vez, las contralorías territoriales han adaptado y adoptado metodologías similares.

Para el efecto, la siguiente definición de beneficios del control fiscal:

(...) La determinación de los beneficios del control fiscal es el instrumento que cuantifica o cualifica el valor agregado generado por el impacto de las actuaciones de control y vigilancia ejercidas por la Contraloría General de la República, a través de funciones de seguimiento a los planes de mejoramiento, observaciones, hallazgos y pronunciamientos. Los beneficios se enmarcan en los conceptos de ahorro y recuperación, en donde ahorro es la erogación dejada de hacer o de pagar por la Entidad o asunto vigilado al realizar una acción preventiva o correctiva, y recuperación es el valor de los bienes o derechos devueltos o reembolsados a la Entidad (...). (CGR, 2017, p.52).

Lo anterior significa que a las contralorías no solamente se les debe medir por el grado de recuperación efectiva del daño patrimonial causado, sino también y con mucho énfasis, por los ahorros y recuperaciones que logren en su función de vigilancia y control, tal como se aludió anteriormente, en el acápite dedicado a las medidas para mejorar el resarcimiento del daño al patrimonio público.

Para ilustrar los efectos e impactos del control fiscal en los últimos años, a continuación, se presentan algunos resultados obtenidos como beneficios del control fiscal.

Tabla 4. Beneficios del control fiscal - total contralorías del país - presupuesto 


\begin{tabular}{llrll}
\hline & \multicolumn{2}{c}{ Total beneficios reportados } & \multicolumn{2}{l}{ Presupuesto contralorías } \\
\hline 2012 & $\$$ & 2.332 .993 .356 .684 & $\$$ & 827.436 .804 .338 \\
\hline 2013 & $\$$ & 3.966 .425 .030 .904 & $\$$ & 832.062 .532 .705 \\
\hline 2014 & $\$$ & 1.561 .439 .867 .657 & $\$$ & 778.148 .942 .004 \\
\hline 2015 & $\$$ & 1.448 .228 .993 .838 & $\$$ & 903.293 .171 .409 \\
\hline 2016 & $\$$ & 279.757 .733 .048 & $\$$ & 873.619 .730 .216 \\
\hline
\end{tabular}

Tabla 5. Beneficios del control fiscal - total contralorías territoriales presupuesto

\begin{tabular}{lllll}
\hline & \multicolumn{3}{l}{ Total beneficios reportados } & \multicolumn{2}{l}{ Presupuesto contralorías } \\
\hline 2012 & $\$$ & 849.731 .919 .381 & $\$$ & 299.247 .874 .506 \\
\hline 2013 & $\$$ & 697.254 .878 .465 & $\$$ & 234.263 .532 .705 \\
\hline 2014 & $\$$ & 1.106 .637 .345 .244 & $\$$ & 244.267 .667 .800 \\
\hline 2015 & $\$$ & 747.052 .781 .357 & $\$$ & 254.760 .877 .433 \\
2016 & $\$$ & 132.996 .560 .080 & $\$$ & 273.365 .758 .663 \\
\hline
\end{tabular}

\subsection{Las tecnologías para mejorar la calidad y cobertura del control}

La Declaración de Asunción, expedida en el encuentro de la Organización Latinoamericana y del Caribe de Entidades Fiscalizadoras Superiores - OLACEFS, celebrado en 2010, en la capital paraguaya, acordó adoptar y difundir entre otros, los siguientes principios de la rendición de cuentas, importantes para un buen gobierno:

“(...) 4. Transparencia de la información.

La publicidad de las actuaciones públicas es premisa fundamental de la transparencia, por lo que la información presentada para los efectos de la rendición de cuentas debe ser confiable, relevante, clara, accesible, comprensible, completa, medible, verificable, oportuna, útil y pública para el ciudadano, promoviéndose el uso de diferentes medios para su comunicación, con el objeto de lograr una adecuada difusión a los actores interesados. Los órganos de control deberán impulsar que la información presentada por las instituciones y funcionarios públicos cuenten con las mencionadas características.

(...) Además, las EFS promoverán un uso intensivo de la tecnología y novedosas formas de comunicación, no sólo para lograr el acceso a la información sino también para efectos

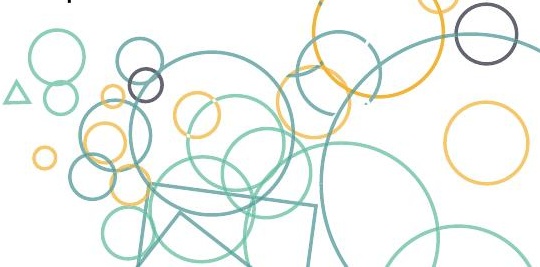




\section{OPPCF}

transaccionales que permitan una gestión pública mucho más eficiente y transparente. Así mismo las EFS promoverán el desarrollo e implementación de normativa, sistemas y, metodologías e indicadores, que permitan realizar mediciones y evaluaciones permanentes de la gestión pública y de la rendición de cuentas (...). (OLACEFS, 2010)

Con ocasión de la expedición de la Ley 1474 de 2011 - Estatuto Anticorrupción -, en la que en su artículo 126 hace referencia a los Sistemas de información en las Entidades de control fiscal, estableció que la Contraloría General de la República, las Contralorías territoriales y la Auditoría General de la República, a través del Sistema Nacional de Control Fiscal - Sinacof, levantarán el inventario de los sistemas de información desarrollados o contratados hasta la fecha de la entrada en vigencia de la ley por parte de las contralorías territoriales para el ejercicio de su función fiscalizadora y propondrán una plataforma tecnológica unificada que procure la integración de los sistemas existentes y permita la incorporación de nuevos desarrollos previamente convenidos y concertados por los participantes de dicho sistema.

De tal forma que, en cumplimiento de lo dispuesto, por su parte la Auditoría General de la República, elaboró un informe como resultado de la encuesta sobre software realizada en octubre de 2011 a las Contralorías territoriales del país, en la que se evidencia que todas las entidades han realizado esfuerzos para mejorar su labor misional. En efecto, el documento señalado logró establecer que en todos los procesos existen aplicaciones, pero el grado de madurez y de estandarización de los mismos es muy bajo; incluso se trata también de esquemas metodológicos y conceptuales, pues existen dos fuertes tendencias en la manera de ejecutar el control fiscal: una orientada al control de gestión y resultados y otra enfocada netamente en los aspectos presupuestales y financieros.

Posteriormente, se adelantó una labor conjunta con el Ministerio de las Tecnologías de la Información y Comunicaciones - MINTIC y algunas contralorías territoriales con el propósito de establecer un sistema único de control fiscal. Al respecto, la línea de acción propuesta se soporta en la heterogeneidad, no tanto en función de los procesos, sino más bien de los sujetos de control a cargo de las contralorías y de la AGR.

El objetivo de dicha actividad, fue presentar una propuesta de procesos y procedimientos en el marco de una futura implementación tecnológica de la solución de Control Fiscal en Línea e identificar las mejores prácticas en cuanto al diseño de aplicativos y los sistemas informáticos encontrados en uso en las Contralorías.

De conformidad con los lineamientos establecidos por las entidades participantes, los ejes temáticos propuestos se desarrollaron en los siguientes procesos: 
- Rendición de cuentas (Incluye la descripción del eje de control a la contratación).

- Proceso Auditor (Incluye la descripción del eje Plan General de Auditoría).

- Responsabilidad fiscal.

- Cobro coactivo.

- Administrativo sancionatorio.

- Participación ciudadana

Al respecto se destacan las conclusiones (MINTIC, AGR 2012) de las cuales se extracta que:

(...) Para la operación del modelo es necesario que el proceso propuesto sea flexible y acorde a la realidad e infraestructura; no solo, de cada contraloría sino de cada sujeto de control. Por lo tanto, deben suponerse niveles de integración medio y bajo que permitan a todos los actores cumplir con sus tareas independientemente del grado de automatización con las que se ejecuten; pues no es obligatorio que la interoperabilidad deba surtirse en esquemas de automatización plena.

(...) Todas aquellas tareas que no puedan ser ejecutadas por el sistema, deben ser remitidas a un back office en el que se fijen estándares de tiempo y resultado.

(...) El equipo de implementación de la estrategia debe tener en cuenta que, en la actualidad, todos los procesos se caracterizan por ser de carácter interinstitucional pero que tal y como se evidenció en el trabajo de campo, hoy día se ejercen actividades aisladas, en cierta medida desordenadas.

(...) Este ejercicio implicaría el desarrollo de mesas técnicas para revisar el grado de madurez del CHIP y del SECOP e identificar las variables y campos de información adicionales; así mismo, el tipo de validación que se realiza durante el cargue. Se hace alusión específica a estos dos sistemas porque en el trabajo de campo, se pudo tener conocimiento de su funcionamiento y porque soporta información clave para la rendición de cuentas en materia presupuestal contable y contractual.

(...) En lo que concierne a requerimientos específicos para las funcionalidades del sistema que soportará los procesos de control fiscal en línea, se considera pertinente reconocer que el diseño de la plataforma debe ser parametrizable de tal suerte que, por cada una de las actividades de los procesos, se permita fijar reglas por cada contraloría y por cada sujeto de control (...).

Finalmente, después de cinco (5) años de presentado el anterior documento, la puesta en marcha de las propuestas allí elaboradas no se habían materializado. Una de las situaciones que afectó el avance de este importante trabajo, fue la posición de la Contraloría General de la República, la que en su momento no concibió que la labor se estuviera realizando por parte de la AGR y las contralorías territoriales, sino que dicha acción debería tener su liderazgo, bajo los parámetros técnicos que ella determinara. En conclusión, es mínimo el avance frente al cumplimiento de ese mandato legal y mucho menor el de consolidar la estructura de un verdadero control fiscal en línea. 


\section{OPPCF}

\subsubsection{Control social para el fortalecimiento del control fiscal.}

Con relación a este tema, la Organización Latinoamericana y del Caribe de Entidades Fiscalizadoras Superiores - OLACEFS, se ha pronunciado acerca de la incidencia ciudadana en el ejercicio del control fiscal:

(...) Este mecanismo de participación ciudadana en el control fiscal está orientado a generar espacios de diálogo y deliberación para influir en la formulación de políticas públicas para el mejoramiento del control fiscal, la gestión pública y la rendición de cuentas institucionales a la ciudadanía. La puesta en marcha de este mecanismo debe partir del reconocimiento de la naturaleza pública de los problemas sobre los cuales desea promoverse la incidencia, así como de la disponibilidad de marcos normativos que facilitan la participación ciudadana en la definición, formulación, implementación, seguimiento y evaluación de las políticas públicas.

El desarrollo de este mecanismo requiere de la movilización de importantes sectores institucionales y sociales además del liderazgo nacional de las EFS. (...) (OLACEFS, 2014, p.10)

Los diagnósticos elaborados sobre la situación del control fiscal territorial en Colombia han evidenciado de forma común, la baja o insuficiente participación por parte de la ciudadanía en el control de los recursos públicos (Ochoa y Charris, 2003; López, 2006; Restrepo, Araujo y Tuta, 2010; Matute, 2011; Peláez, Tuta y García, 2013). En este sentido, se manifiesta una problemática asociada no solo al cumplimiento del mandato establecido en el artículo 270 de la Carta Política, sino también al deber que tienen todos los ciudadanos de ejercer el control social para contribuir a la eficiente y eficaz destinación de los recursos públicos.

Según los reportes de los procesos de responsabilidad fiscal en curso, solo el $2 \%$ de estos tienen su origen en las denuncias realizadas por la ciudadanía (AGR SIREL-SIA, 2017), porcentaje que se encuentra por debajo del promedio de otras participaciones de acuerdo con la Encuesta de Cultura Política del DANE 2017, la cual reporta una participación en acciones comunitarias de $13,5 \%$; en recreación, cultura y deporte de $11,7 \%$ y en actividades de tipo espiritual o religioso de 74,5\% (DANE, consultado en diciembre de 2017). Estos hechos indican que la ciudadanía colombiana, a pesar de reconocer la problemática en relación con la desviación de recursos públicos y la necesidad de realizar control social sobre el erario, no participa de estas con el mismo interés que en otro tipo de actividades (en promedio 25\%, DANE, 2017).

La baja participación en el control social por parte de la ciudadanía puede estar explicada por varias razones: desconocimiento de los instrumentos para ejercer control social y control fiscal (DANE, 2017), indiferencia frente a la problemática nacional (López, 2013), falta de credibilidad frente a las instituciones del Estado (CNCLCC, 2014), riesgos en la integridad o seguridad personal y familiar (El País, 2017); sin embargo, Olken (2007), en sus estudios sobre corrupción demuestra que la participación ciudadana tiene impacto, bajo un conjunto limitado de 


\section{circunstancias:}

(...) La evidencia empírica sugiere que el monitoreo ciudadano puede ser efectivo en circunstancias en las que hay poca libertad o intereses privados involucrados. Por ejemplo, los programas que proporcionan bienes privados, como alimentos subsidiados, educación o atención médica, donde los ciudadanos tienen un interés personal en garantizar que se entreguen los productos y se minimice el desvío de recursos, pueden ser candidatos apropiados para el monitoreo de base. Para los bienes públicos en los cuales los incentivos para monitorear son mucho más débiles, como los proyectos de infraestructura, los resultados muestran que el uso de auditores profesionales puede ser mucho más efectivo (...) (Olken, 2007, p. 244).

En este sentido, el impacto de la participación ciudadana en el ejercicio de control social, es limitado en ciertas circunstancias y sus efectos no son los mismos en la totalidad de sectores y categorías en que se dividen los recursos públicos. Por esta razón, las propuestas en las que se involucre la participación de la ciudadanía deben contemplar estas restricciones y contener la focalización de los mecanismos utilizados hacia las áreas o sectores en donde se evidencian mayores impactos.

\section{De otra parte, la Comisión Nacional Ciudadana para la Lucha Contra la Corrupción (CNCLCC) en} su informe de 2014 destacó:

(...) la importancia del control ciudadano para la construcción de paz en Colombia, teniendo en cuenta que la corrupción y los obstáculos a la participación ciudadana podrían afectar la implementación de los acuerdos de paz. La CNCLCC resaltó la necesidad de lograr mayor apertura por parte de las autoridades nacionales y locales para proporcionar información a la ciudadanía y rendir cuentas sobre el uso de recursos públicos, así como promover la participación efectiva de grupos ciudadanos afectados por el conflicto armado (...) (CNCLCC, 2014).

Dicha Comisión además indica que:

(...) Es urgente que durante los próximos años se logren resultados efectivos y evidentes para la ciudadanía en materia de prevención y sanción de corrupción en ámbitos como las inversiones públicas del Estado, en los cargos públicos de alto nivel en todas las ramas del poder, en el sistema judicial, en el sistema electoral y los partidos políticos, entre otros campos. Para esto, resulta fundamental una mayor coordinación entre distintas instancias del Estado para combatir la impunidad de los casos de corrupción que afectan a toda la sociedad y de esta manera empezar a generar confianza en la misma (...) (Olken, 2007, p. 244).

En consecuencia, habrá que fortalecer la participación ciudadana con las siguientes medidas:

- Convocar a la ciudadanía para el ejercicio de control social, focalizando su participación en los sectores donde están involucrados los intereses privados de la ciudadanía como: salud, educación, vivienda, servicios públicos domiciliarios, entre otros.

- Diseñar e implementar un programa de pedagogía en control social impulsando redes con distintos actores de la sociedad civil (Peláez, Tuta y García, 2013), en los que se generen 


\section{OPPCF}

estrategias conjuntas con los organismos de control (Fiscalía General de la Nación, Procuraduría General de la República, Contraloría General de la República, Auditoría General de la República y Contralorías Territoriales).

- Diseñar e implementar políticas públicas de participación ciudadana para la lucha contra la corrupción en el ámbito territorial, de acuerdo con las políticas nacionales actuales: Ley 1474 de 2011 (Estatuto Anticorrupción), CONPES 167 de 2013 (Política Anticorrupción), Ley 1712 de 2014 (Ley de Transparencia), Ley 1757 de 2015 (Ley de Promoción y Protección de la Participación Ciudadana), entre otras.

- Brindar información a los ciudadanos, mediante la elaboración de aplicativos informáticos de fácil acceso en la que se superpongan datos georreferenciados de la ejecución de contratos o intervenciones con recursos públicos (planes, programas, proyectos) en los sectores de salud, educación, vivienda, servicios públicos domiciliarios, entre otros, con sus objetos y montos. En ese sentido, se buscaría fortalecer los desarrollos e iniciativas del MINTIC, utilizando como punto de partida las políticas públicas territoriales de lucha contra la corrupción.

- Diseñar e implementar con el sector privado programas de responsabilidad social, que impulsen procesos de formación de la ciudadanía en identificación de riesgos en la prestación de servicios y mecanismos de monitoreo de recursos públicos en los sectores de mayor impacto.

- Generar estudios especializados, guías o instructivos elaborados especialmente para el monitoreo ciudadano, con herramientas de análisis y argumentación que puedan ser verificados en los contextos locales.

- Implementar en el ámbito territorial mecanismos para el fortalecimiento de veedurías ciudadanas en articulación con las políticas nacionales.

- Diseñar e implementar proyectos de cooperación y alianzas estratégicas con los actores involucrados en la lucha contra la corrupción (sector privado, academia, sector público, organismos de control, organizaciones no gubernamentales, entre otros) para que, con el apoyo de la ciudadanía, se construyan redes de alertas tempranas anticorrupción.

\subsubsection{Ampliación del periodo constitucional del Auditor General de la República}

Este tema ha sido ampliamente debatido en diferentes instancias a nivel nacional, es así que, en el informe de ponencia para primer debate al proyecto de acto legislativo 072 de 2013, presentado ante la Cámara de Representantes, por medio del cual se propuso la modificación 
del artículo 274 de la Constitución Política de Colombia, se tuvieron en cuenta entre otras las siguientes consideraciones:

- Actualmente el periodo constitucional del Auditor General de la República es de dos (2) años, mientras que el periodo de los contralores es de cuatro (4) años. Es importante señalar que la Constitución de 1991 estableció periodos para las autoridades públicas así: cuatro (4) años para el Presidente de la República, Procurador General de la Nación, Defensor del Pueblo, y Fiscal General de la Nación. En el ámbito territorial los Gobernadores, Alcaldes y Personeros, también cuentan con un periodo de (4) cuatro años.

- Los planes y programas proyectados por los Contralores se desarrollan en períodos de cuatro (4) años establecidos por la Constitución y la Ley, el seguimiento y evaluación a que está sometida su gestión, también debería realizarse en un período similar, lo que permitiría efectuar evaluaciones globales al vencimiento del período, verificando el grado de cumplimiento de las metas trazadas por las Contralorías y su contribución a la lucha contra la corrupción y la ineficiencia e ineficacia en la gestión fiscal.

- El periodo de dos (2) años, previsto en la actual Constitución no es suficiente para poder ejecutar proyectos sólidos para la mejora del control fiscal, máxime cuando la principal misión de la Auditoría General es la coadyuvancia para la mejora del control fiscal, lo cual conlleva una serie de estrategias a mediano y largo plazo que no es posible ejecutarlas en un periodo tan corto.

- Con el actual esquema, el ejercicio del control fiscal por parte de la AGR, está condicionado por un criterio cortoplacista que en nada contribuye al desarrollo y mejoramiento de las Contralorías como órganos de control que combaten la corrupción y buscan el resarcimiento al daño patrimonial al Estado.

- El periodo del Auditor General de la República ampliado, permitirá que sus funciones se desarrollen en la forma requerida y arrojen los resultados esperados por la ciudadanía, garantizando que los recursos públicos asignados a las Contralorías se administren de manera eficiente y se destinen a la satisfacción del cometido estatal, para el cual fueron creadas.

Por lo anterior, es pertinente insistir en la necesidad de ampliar el período del Auditor General de la República a cuatro años, como el de los demás organismos de control. Igualmente se propone que el inicio del periodo no coincida con el del Contralor General de la República.

\subsection{CONCLUSIONES}

En los párrafos precedentes se ha expuesto lo que, a juicio de la AGR, constituyen temas fundamentales que deben ser abordados por las instancias correspondientes, el Congreso de la República, el Gobierno Nacional, las Contralorías y la misma Auditoría General de la República, para definir el futuro inmediato de los organismos de control fiscal y su efectividad en la lucha contra la corrupción. 
Para ello se han tratado los requerimientos legales y técnicos que posibilitarían una reforma que permita una eficiente y efectiva estructura del control fiscal territorial. En consecuencia, las medidas que han de adoptarse en cada caso serían de orden constitucional, legal y también aquellas que pueden y deben abordarse por parte de los mismos organismos de control sin necesidad de reforma jurídica.

\section{Propuestas de reforma constitucional:}

1.1. Fortalecimiento y articulación de la actual estructura del control fiscal. Creación Constitucional de un Sistema Nacional Territorial de Control Fiscal, que amplíe, mejore e institucionalice el SINACOF de la CGR; integrado por todas las instituciones de control fiscal de primer y segundo nivel y por las instituciones representativas del control interno y representantes de la sociedad civil organizada.

1.2. Elevar a rango constitucional el control fiscal preventivo establecido en el Estatuto Anticorrupción. Retomar la función de advertencia o su equivalente, como producto del ejercicio inmediato del control fiscal posterior, frente al riesgo de pérdida de patrimonio público.

\subsection{Crear una jurisdicción especial para los procesos de responsabilidad fiscal.}

1.4 Ampliar a cuatro años el periodo del Auditor General de la República.

\section{Propuestas de reforma legal:}

2.1 Supresión o modificación de la Ley 617 de 2000 en lo relacionado con los presupuestos de las contralorías y supresión del artículo 15 de la Ley 330 de 1996, en cuanto a la prohibición a las contralorías departamentales de contratar por prestación de servicios. Adoptar una nueva metodología para calcular el presupuesto de las contralorías, estableciendo para todas, la posibilidad legal de incluir en el presupuesto el rubro de inversión.

\subsection{Reglamentar la carrera administrativa del control fiscal territorial.}

2.3 Independencia y autonomía de los organismos de control fiscal territorial. La meritocracia, como requisito único para la selección de contralores territoriales y sus equipos directivos. La elección por cuatro años, con periodos no coincidentes con los de los gobernantes vigilados.

2.4 Liberar a las contralorías territoriales de la función de adelantar y tramitar hasta su culminación los procesos de responsabilidad fiscal y de cobro coactivo, y trasladar tal función en una jurisdicción real, como la de lo Contencioso Administrativo, adicionando los procesos de responsabilidad fiscal y jurisdicción coactiva en los listados del artículo 104 de la Ley 1437 de 2011.

2.5. Fortalecimiento de las contralorías territoriales, dotándolas de los recursos técnicos, tecnológicos, presupuestales y de talento humano calificado, de manera que dispongan de la suficiente capacidad gerencial para cumplir con la misión constitucional asignada.

2.6 Establecer sanciones adicionales a las señaladas en la Ley 42 de 1993, para los gestores de recursos públicos por el no fenecimiento de cuentas; conceptos desfavorables sobre la calidad y eficiencia de control fiscal interno y por la no razonabilidad de los estados contables.

2.7 Articular el sistema de control interno y el control fiscal y establecer nuevas atribuciones a oficinas de control interno.

\section{Otras acciones para la eficacia del control fiscal que no requieren reforma jurídica:}

3.1 Implementación del ejercicio inmediato del control posterior. 
3.2 Fortalecimiento de la evaluación de la gestión y resultados a través del control al Plan de Desarrollo.

Finalmente, por su importancia la AGR recomendó con base en los anteriores análisis, en el mismo documento de respuesta al CONPES 167, que a la hora de un gran debate sobre la reforma al Sistema de Control Fiscal, se tuviera muy en cuenta las recomendaciones de la Misión de Expertos (AGR y Banco Mundial, 2011), y que se dejara abierta la puerta para desarrollar los contenidos normativos de una reforma legal que posibilitara el control preventivo y una nueva estructura del control fiscal.

Efectivamente, el documento atrás compartido, elaborado por la Auditoría General de la República en desarrollo de la actividad número 110 (5.20) del componente principal de la Política Pública Integral Anticorrupción (PPIA), del CONPES 167 de 2013, a título de propuesta sobre la estructura del control fiscal territorial, fue tenido como insumo en las distintas mesas de discusión del Proyecto de Acto Legislativo 39 de 2019 Senado, 355 de 2019 Cámara "Por medio del cual se reforma el régimen de control fiscal" (Primera vuelta), cuyo texto definitivo fue publicado por Decreto 1275 de 18 de julio de 2019 y que culminó con el Acto Legislativo 004 de 18 de septiembre de 2019, cuyas principales reformas se exponen en el capítulo II de este mismo libro, denominado "Generalidades sobre la trayectoria legal, jurisprudencial y de regulación, del control fiscal en Colombia".

En consecuencia, los análisis elaborados en el documento de diciembre de 2017 y expuestos atrás, no solo mantienen su vigencia sino que constituyen elementos de análisis sustancial, para tener en cuenta al momento de la construcción de políticas públicas de control fiscal en el país.

\subsection{BIBLIOGRAFÍA}

- Auditoría General de la República y Banco Mundial (2011). Sistema Nacional de Control Fiscal Territorial en Colombia". Imprenta Nacional.

- Auditoría General de la República - Peláez, Juan., Tuta, Guillermo y García., Gustavo (2013). La Impostergable Reingeniería del Control Fiscal Territorial. Documento para el debate sobre una política pública del control fiscal. Revista Sindéresis.

- Auditoría General de la República, 2002. El Nuevo Sistema de Control Fiscal Colombiano Sinopsis. Separata especial. Revista Sindéresis.

- Auditoría General de la República. - Ossa, Carlos (2006). Reformar el Control Fiscal Territorial. Necesidad inaplazable para optimizar las finanzas territoriales. Revista Sindéresis 


\section{OPPCF}

- Auditoría General de la República. Rendón, Álvaro- Suárez, Daniel (2001). Bases para un Nuevo Modelo de Control en Colombia. Ponencias II Foro Nacional de Control.

- Base de datos: Auditoría General de la República SIREL-SIA. (2017). Generada en noviembre de 2017.

- Carvajal, L. y Amaya, R. (2004). Colombia e Indonesia: lejanía geográfica, cercanía temática (un ejercicio comparativo)*. Bogotá, Colombia: Embajada de Indonesia en Colombia.

- Contraloría denuncia billonarios sobrecostos en Reficar. (26 de enero de 2016) ElEspectador. Recuperado de http://www.elespectador.com/

- Comisión Nacional Ciudadana para la Lucha Contra la Corrupción (2014). Cuarto Informe de la CNCLCC: «Ciudadanía califica la corrupción como uno de los problemas más graves que enfrenta el país». Bogotá, Colombia. Recuperado de: http://ciudadanoscontralacorrupcion. org

- Contraloría General de la República. Informe de gestión al Congreso y al Presidente de la República 2016-2017. Recuperado de: http://contraloria.gov.co

- DANE (2017). Resultados de la Encuesta de Cultura Política 2017. Bogotá, Colombia: DANE. Recuperado de: http://www.dane.gov.co

- Diaz, Camilo (16 de enero de 2016). La locura de vender Isagén costará \$70.000 millones. Revista Dinero. Recuperado de http://www.dinero.com

- ¿ ¿Funcionará el proyecto de pagar a quienes denuncien corrupción? (3 de marzo de 2017)

- Contraloría denuncia billonarios sobrecostos en Reficar. (26 de enero de 2016) El Pais.com. co. Recuperado de http://www.elpais.com.co

- Gómez, Iván Darío, Céspedes, Fredy (2017) Reestructuración y Fortalecimiento del Control Fiscal. Propuesta para la reforma del control fiscal en Colombia. Documento de trabajo.

- Gómez, Iván Darío, Ordóñez, Tatiana (2010). Vulnerabilidad y Sofisticada Corrupción: Desafío para la Auditoría Gubernamental en Colombia. Revista Internacional LEGIS de Contabilidad y Auditoría (44), 17-36.

- Informe de ponencia para primer debate al proyecto de acto legislativo 072 de 2013 cámara. (2013). Recuperado de http://www.imprenta.gov.co/gacetap/gaceta.indice?v num $=825 \&$ v anog $=2013$

- López, Clara (2006). Control Fiscal Territorial. Realidad y propuesta de Mejoramiento. Bogotá. 
Universidad del Rosario-GTZ.

- López, Clara (2013). Colombia, un país diferente. Las 2 orillas. Recuperado de: https://www. las2orillas.co

- Ministerio de Tecnologías de Información programa Gobierno en Línea y Auditoría General de la República (2012). Documento propuesta de Procesos y Procedimientos para el Nuevo Esquema de Control Fiscal en Línea.

- Naranjo, Rodrigo. (2007) Eficacia del Control Fiscal en Colombia. Derecho Comparado, Historia, Micro organizaciones e Instituciones. Universidad del Rosario.

- Ochoa, Héctor, Charris, Sandra. (2003) Propuesta de un Modelo de Control Fiscal para el Estado Colombiano: El Sistema de Control Fiscal Nacional. ICESI Estudios Gerenciales, (89)

- Olken, B. (2007). Monitoring Corruption: Evidence from a Field Experiment in Indonesia. Boston, USA: Harvard University and National Bureau of Economic Research.

Organización Internacional de las Entidades Fiscalizadoras Superiores OLACEFS (2007). Declaración de México sobre independencia de las EFS (ISAll-10). Recuperado de http//www. intosai.org

Organización Internacional de las Entidades Fiscalizadoras Superiores OLACEFS (2009). Declaración de Asunción Principios sobre Rendición de Cuentas. Recuperado de http// https:// www.agn.gov.ar

Organización Internacional de las Entidades Fiscalizadoras Superiores OLACEFS (2014). Buenas prácticas para el fortalecimiento de las relaciones entre las EFS y la Ciudadanía.

Recuperado de http://www.olacefs.com

Ordóñez, Tatiana (2007). La Responsabilidad Fiscal en Colombia y la Imposibilidad del Resarcimiento Patrimonial. Revista IUSTA Universidad Santo Tomas. 1 (26), 126

Real Academia Española. (2001). Diccionario de la lengua española (22. ${ }^{\mathrm{a} e d .}$.). Consultado en http://www.rae.es/rae.html

Restrepo, M., Araujo, R y Tuta, G. Control Fiscal Territorial. Validación de un modelo de la gestión y los resultados de las contralorías territoriales en Colombia. Universidad del Rosario, Agencia de Cooperación Técnica Alemana GTZ, Bogotá.

Semana en vivo (10 de febrero de 2016). ¿Cuánto fue realmente lo que se robaron en Reficar?

Saqueo de la corrupción equivale a casi un billón de pesos por semana. (26 de febrero de 2017) El Tiempo. Recuperado de http://www.eltiempo.com/ 